Aksaray University
Journal of Science and Engineering
e-ISSN: 2587-1277
http://dergipark.gov.tr/asujse
http://asujse.aksaray.edu.tr

Research Article

\title{
Medicinal Plants of Flora of KSU Avsar Campus (Kahramanmaras) and Surrounding Areas
}

\author{
Yusuf Ziya Kocabas ${ }^{*}$, Adem Erol², Oguzhan Aktolun ${ }^{3}$ \\ ${ }^{1}$ KSU, Vocational School of Turkoglu, Department of Medicinal and Aromatic Plants, Kahramanmaras-Turkey \\ ${ }^{2}$ KSU, Faculty of Agriculture, Department of Field Plants, Kahramanmaras-Turkey \\ ${ }^{3}$ KSU, Graduate School of Natural and Applied Sciences Department of Biology, Kahramanmaras-Turkey
}

-Received Date: 19 Apr $2017 \quad$-Revised Date: 06 Jun $2017 \quad$-Accepted Date: 02 Jul $2017 \quad$-Published Online: 10 Jul 2017

\begin{abstract}
Kahramanmaras is at the point of the intersection of Mediterranean and Irano-Turanian phytogeographical regions which are very important in terms of geographical location and plant geography. This area has a rich and various vegetation structure due to complex physical geographical structure and other environmental factors. It is crucial to protect by determinating this rich biodiversity. The research area is located in the Kahramanmaras province and on the C6 square in Davis's grid system. The campus of KSU and its surrounding area is located in the Ceyhan Valley. The native flora of this area has been extensively destroyed by anthropogenic effects. This study was carried out between 2015 and 2017 and the plants used in medicinal and aromatic purposes of the native flora were investigated. As a result, it was determined that 47 plant taxa belonging to 27 families for used medically. In terms of species number, the largest families are as following; Lamiaceae (7), Asteraceae (5), Rosaceae (3). These plant taxa were alphabetically indicated according to their family names, Latin and local names as well as with their used parts and usage purposes.
\end{abstract}

\section{Keywords}

Flora, Kahramanmaras, Medicinal Plant

${ }^{*}$ Corresponding Author: Yusuf Ziya Kocabas, kocabasyz@ksu.edu.tr 


Aksaray University
Journal of Science and Engineering
e-ISSN: 2587-1277
http://dergipark.gov.tr/asujse
http://asujse.aksaray.edu.tr

Research Article

\title{
KSÜ Avşar Yerleşkesi (Kahramanmaraş) ve Çevresi Florasının Tıbbi Bitkileri
}

\author{
Yusuf Ziya Kocabaş ${ }^{1 *}$, Adem Erol ${ }^{2}$, Oğuzhan Aktolun ${ }^{3}$
}

${ }^{1}$ KSÜ, Türkoğlu MYO Tıbbi ve Aromatik Bitkiler Bölümü, Kahramanmaraş 46100, Türkiye

${ }^{2}$ KSÜ, Ziraat Fakültesi Tarla Bitkileri Bölümü, Kahramanmaraş 46100, Türkiye

${ }^{3}$ KSÜ, Fen Bilimleri Enstitüsü Biyoloji Anabilim Dalı, Kahramanmaraş 46100, Türkiye

-Gönderi Tarihi: 19 Nis 2017

-Düzeltme Tarihi: 06 Haz 2017

-Kabul Tarihi: 02 Tem 2017

-Cevrimiçi Yayın Tarih: 10 Tem 2017

\section{Özet}

Kahramanmaraş coğrafik konumu ile bitki coğrafyası açısından çok önemli olan Akdeniz ve İran-Turan fitocoğrafik bölgelerinin kesişme noktasındadır. Bu bölge, farklı coğrafik yapı ve çevresel faktörlerin etkisi ile zengin ve çeşitli bir vejetasyon yapısına sahiptir. Bu zengin çeşitliliğin belirlenerek korunması çok önemlidir. Araştırma alanı Kahramanmaraş ilinde Davis'in grid sisteminde C6 karesindedir. KSÜ kampüsü ve çevresi Ceyhan Vadisi'nde yer almaktadır. Bu bölgedeki doğal flora insan etkisi ile aşırı zarar görmüş durumdadır. Bu çalışma 2015-2017 yılları arasında yürütülmüş ve doğal florada bulunan bitki türlerinden tıbbi olarak kullanılanlar araştırılmıştır. Sonuç olarak tıbbi açıdan kullanılan 27 familyaya ait 47 bitki taksonu belirlenmiştir. Tür sayısı bakımından en büyük familyalar sırasıyla; Lamiaceae (7), Asteraceae (5), Rosaceae (3)'dir. Bu bitki taksonlarının latince ve yerel isimleri, kullanılan kısımları ve kullanım amaçları familya isimlerine göre alfabetik olarak verilmiştir.

\section{Anahtar Kelimeler}

Flora, Kahramanmaraş, Tibbi Bitki

*Sorumlu Yazar: Yusuf Ziya Kocabaş, kocabasyz@ksu.edu.tr 


\section{GIRIŞ̧}

Doğal kaynaklar insanlık tarihi boyunca kullanılagelmiştir. Bu kullanımlar arasında; gıda, ilaç, çay, baharat, yakacak, kozmetik, boya, silah, büyü, hayvan yemi sayılabilir. İnsan ve çevresi arasında devam eden etkileşim diğer canlı grupları ile vazgeçilemez bir bağ oluşmasına neden olmuştur. Bitkiler insanlar tarafından günlük hayatta birçok alanda tercih edilmektedir. $\mathrm{Bu}$ durum tüm dünya tarafından benimsenen ve önemli araştırmaların yapıldığı etnobotanik bilim dalının ortaya çıkmasına neden olmuştur. Etnobotanik kelime bakımından; etno:insanlar ile ilgili araştırmalar, botanik:bitki bilimi anlamına gelmesinin yanı sıra kültürel ve sosyolojik açıdan farklı olan toplumlardaki bitki-insan ilişkileri anlamını da taşır [1-3]. Bir bilim dalı olarak gelişmeye başladığı 19 yy'ın sonunda etnobotanik başta Dünya Sağlık Örgütü (WHO) olmak üzere birçok büyük ilaç şirketi bu alandaki araştırmalara destek vermiştir [4]. Farklı toplumlarda kullanılan geleneksel etnobotanik bilgiler ve bunların yaygın etkisi çeşitli araştırmalara konu olmuştur [3, 5-9]. Geleneksel tedavi yöntemlerinin insan sağlığ üzerindeki rolünün fark edilmesi ve bu alandaki araştırmaların artması üzerine WHO geleneksel tedavi yöntemlerinin yaygınlaşması ve standardizasyonu için “Geleneksel Tıp Stratejileri” programını başlatmıştır [10]. Etnobotanik araştırmalar sonucu elde edilen veriler uzun bir zaman süreci sonucunda ve deneme-yanılma yoluyla oluşan bilgilerin bilimsel bakış açısıyla değerlendirilmesini sağlamaktadır. Son yıllarda malaria hastalığına karşı geliştirilen ilacın içindeki artemisin (Artemisia апnиa L.) etnobotanik kayıtlar sayesinde keşfedilmiştir [11]. Farklı toplum ve kültürlerde buna benzer keşfedilmeyi bekleyen daha birçok bitki, kullanım şekli ve tedavi yöntemi vardır. Etnobotanik çalışmalar sayesinde bölgesel bazda elde edilen bilgilerin değerlendirilmesi kadar kuşaklar arasında aktarılması da önemlidir [3, 12, 13]. Türkiye sahip olduğu zengin kültürel mirasın içinde yer alan etnobotanik bilgi birikimi ile tıbbi bitki alanında potansiyel bir kaynaktır [14]. Bu durumun en önemli sebebi Türkiye'nin sahip olduğu farklı iklim ve coğrafik yapıdan dolayı değişik vejetasyonlardaki zengin flora ve biyoçeşitliliktir. Dünyada bulunan yaklaşık 400,000 bitki türünün 11,707'si Türkiye'de bulunmaktadır ve bunlarında \% 33'ü endemiktir [15-17].

$\mathrm{Bu}$ araştırma kapsamında Kahramanmaraş Sütçü İmam Üniversitesi Avşar Kampüsü ve çevresindeki alanda tespit edilen bitki türleri tıbbi kullanımları açısından değerlendirilmiştir. Tespit edilen bitkilerin kullanılan kısımları, ne şekilde değerlendirildikleri ve bazı taksonların fotoğrafları da verilerek bu alanda yapılan çalışmalara katkı sunulması amaçlanmıştır. 


\section{MALZEME VE YÖNTEM}

Çalışmanın yürütüldüğü il Kahramanmaraş; 14,327 km² yüzölçümü ve sahip olduğu 11 ilçe ile Akdeniz bölgesinin doğusunda (K:37¹1'038" ve D:36 15'037") yer alır (Şekil 1). Kent 1,089,038 nüfusa sahiptir [18]. Kahramanmaraş zengin biyolojik çeşitliliğe sahiptir, bunun nedeni Akdeniz ve İran-Turan fitocoğrafik bölgelerinin geçiş kuşağında bulunması ve Anadolu Diyagonali'nin güneyinde iki kola ayrıldığı bölgede yer almasıdır [16]. Bölgede kırmızımsıkahverengi Akdeniz toprakları ile kahverengi ve kahverengi-kireçsiz orman toprakları bulunur [19]. Çalışma alanında kil, siltli kil, kumlu kil, siltli killi tın gibi toprak türlerine sahiptir [21]. Akdeniz ikliminin hâkim olduğu bölgede yazları sıcak ve kurak, kışları 1lık ve yağmurlu geçer $[20]$.

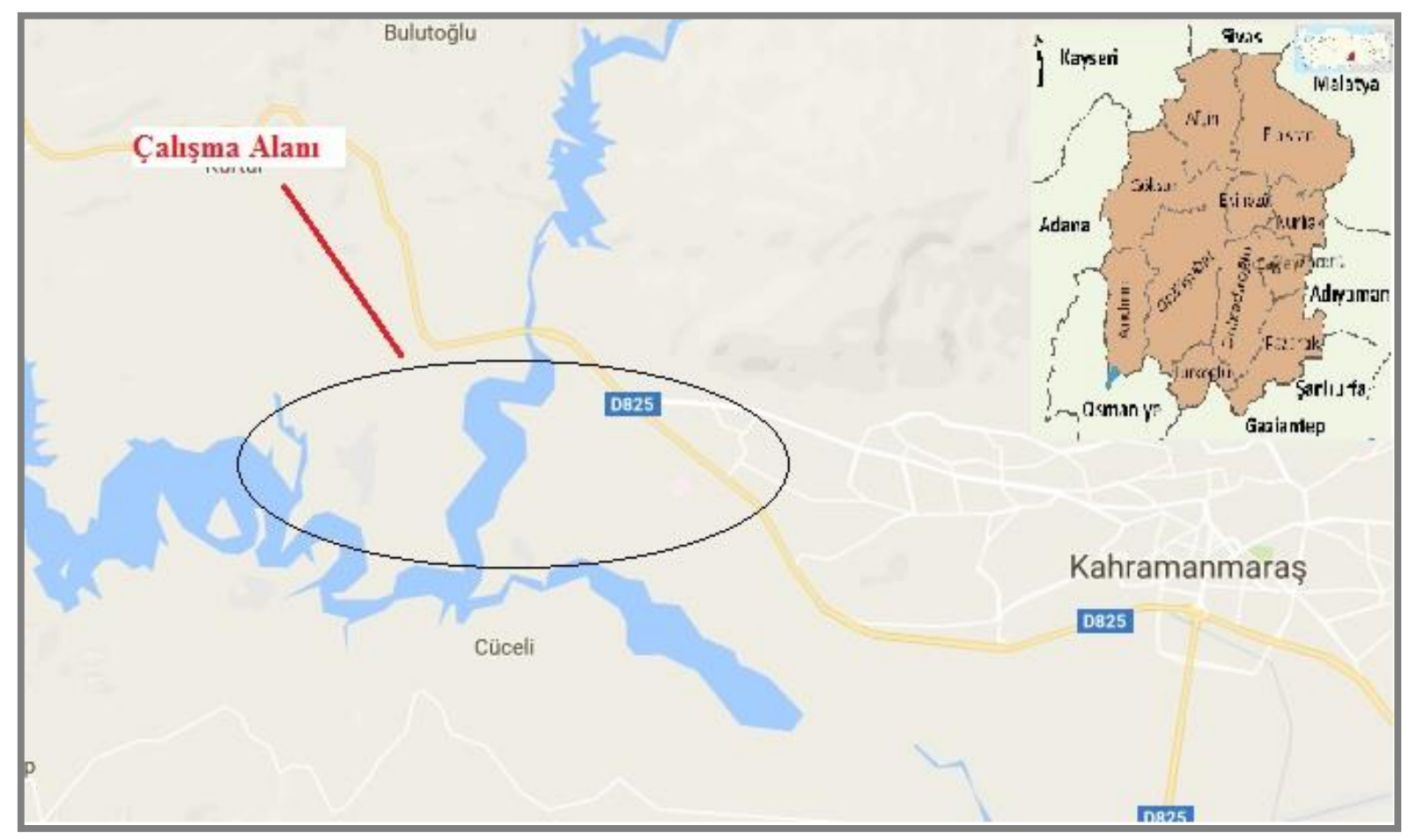

Şekil 1. Çalışma alanı haritası [18]

$\mathrm{Bu}$ çalışma 2015-2017 yılları arasında Kahramanmaraş Sütçü İmam Üniversitesi Avşar Kampüsü ve çevresindeki bölgede bulunan Hasancıklı, Avşar, Kılavuzlu, Kavlaklı, Bulutoğlu, Kürtül, Sarıçukur mahallelerinde yürütülmüştür. Vejetasyon dönemlerinde yapılan arazi gezileri ile türler tespit edilerek, aynı bölgede yerleşik halka bu türlerin yöresel isimleri, kullanılan kısımları ne amaçla ve nasıl kullanıldıkları yönünde sorular yöneltilmiş ve fotoğrafları çekilmiştir (Şekil 4). Toplanan bitkilerin teşhisleri Türkiye Florası'na göre yapılmıştır [16]. Tespit edilen bitkilerin; familyası, kullanılan kısımları, hangi amaçla nasıl kullanıldıkları ve yöresel adları verilmiştir (Tablo 2). 


\section{BULGULAR VE TARTIŞMA}

Bu araştırma ile Kahramanmaraş Sütçü İmam Üniversitesi Avşar Kampüsü ve çevresindeki florada bulunan 27 familya ve 44 cinse ait toplam 47 farklı bitki taksonu tespit edilmiştir. Tespit edilen bitki taksonları araştırma alanında ve Kahramanmaraş il merkezinde yerleşik halk tarafından farklı tıbbi amaçlar için kullanılmaktadır. Tespit edilen bitki taksonları sistematik açıdan değerlendirildiğinde; tespit edilen bitkilerin \%68'i otsu, \%19'u ağaç ve \%13'ü çalı formundadır. Familya bazında ise ilk sırayı Lamiaceae (7 takson), ikinci sırayı Asteraceae (5 takson), üçüncü sırayı Rosaceae, Brassicaceae ve Moraceae (3 takson), Malvaceae, Solanaceae, Caryophyllaceae ve Convolvulaceae ( 2 takson) diğer familyalar ise 1'er taksona sahiptir (Tablo 1). Bu sonuç bu alanda yapılmış diğer çalışmalarla benzerlik taşımaktadır [3, 22-23]. Bitkilerin genel olarak; yaprakları (\%58), meyveleri (\%13), toprak üstü kısımları (\%12), tohumları (\%8) ve diğer kısımları farklı amaçlar için kullanılmaktadır (Şekil 2).

Tespit edilen bitkiler doğadan toplanarak (37 takson) veya (10 takson) kültürü yapılarak kullanılmaktadır. Tespit edilen taksonlar; sindirim rahatsızlıkları için, çeşitli yara tedavileri için, romatizmal ağrılar için, afrodizyak olarak, saç bakımı için, damar açıcı olarak, kas krampları için, nefes açıcı olarak, kan ve kalp hastalıkları için, iştah açıcı olarak ve soğuk algınlığı için kullanılmaktadır (Şekil 3). Bu çalışmada tespit edilen bitki taksonlarının 34'ü taze olarak tüketilirken 13’ü kuru olarak kullanılmaktadır. Bazı taksonların (Crataegus monogyna Jacq. var. monogyna) odunsu gövdesi kullanılırken, Solanum americanum Mill.'in kök kısmı kullanılmaktadır (Tablo 2).

Tespit edilen bitkilerden bir kısmı gıda olarak kullanılmaktadır, gıda olarak tercih edilen bazı taksonlar tıbbi olarak da değerlendirilmektedir. Arum türleri bölgede "Tirşik" olarak bilinmektedir, içerdiği alkaloitlerden dolayı zehirlidir [22]. Çiğ yaprakların yoğurt, bulgur ve nohut eklenmesiyle fermente edilerek hazırlanan "Tirşik çorbası" sindirim sistemine olan faydasından dolayı gıda olarak tüketilmektedir. Nasturtium officinale (1spatan) bağışıklık sistemini güçlendirdiği düşüncesiyle özellikle ilkbaharda yemekler ile birlikte tüketilmektedir. Abelmoschus esculentus gida olarak tercih edilmesinin yanında meyvelerinden hazırlanan lapa sinüzit tedavisinde kullanılmaktadır. Bölgede yaygın olarak yetişen dut türleri gıda olarak tüketilmekle beraber; Morus alba sindirim sistemi rahatlatıcısı olarak ve meyvesinden yapılan dut pekmezi ise kan yapıcı olarak kullanılmaktadır. Morus nigra (urmu dutu) meyvelerinden elde edilen şerbeti nedeniyle bölgede sevilerek tüketilmektedir. Bu türün meyvesi ağız yarası tedavisinde de kullanılmaktadır. 
Tablo 1. Çalışmada tespit edilen familyalara ait takson sayıları değerleri

\begin{tabular}{clc}
\hline Sira & Familya adı & Takson Sayısı \\
\hline 1 & Lamiaceae & 7 \\
\hline 2 & Asteraceae & 5 \\
\hline 3 & Rosaceae, Brassicaceae, Moraceae & 3 \\
\hline 5 & Malvaceae, Solanaceae, Caryophyllaceae, Convolvulaceae & 2 \\
\hline 6 & Diğer familyalar & 1 \\
\hline
\end{tabular}

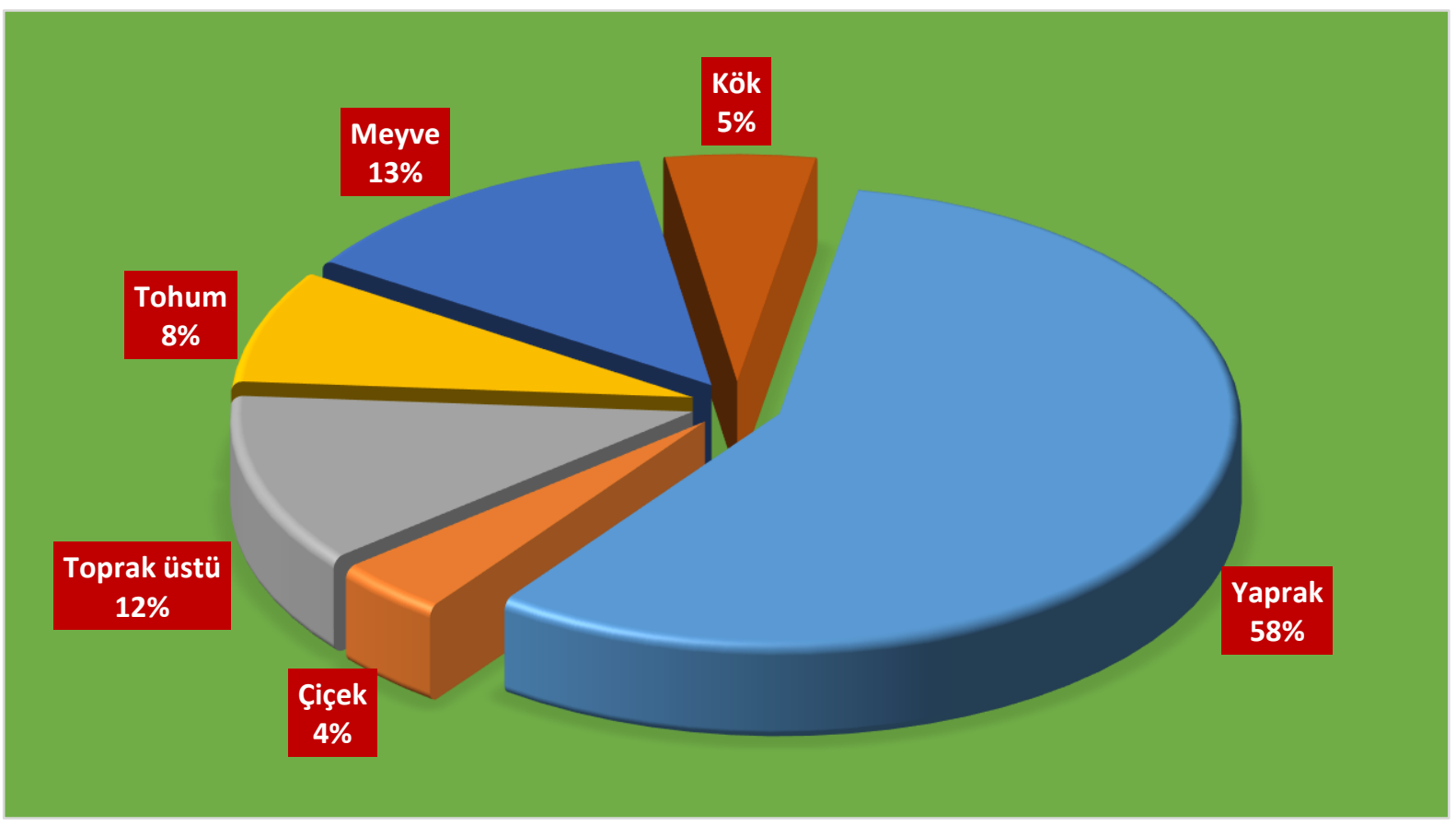

Şekil 2. Çalışmada tespit edilen bitkilerin kullanılan kısımları

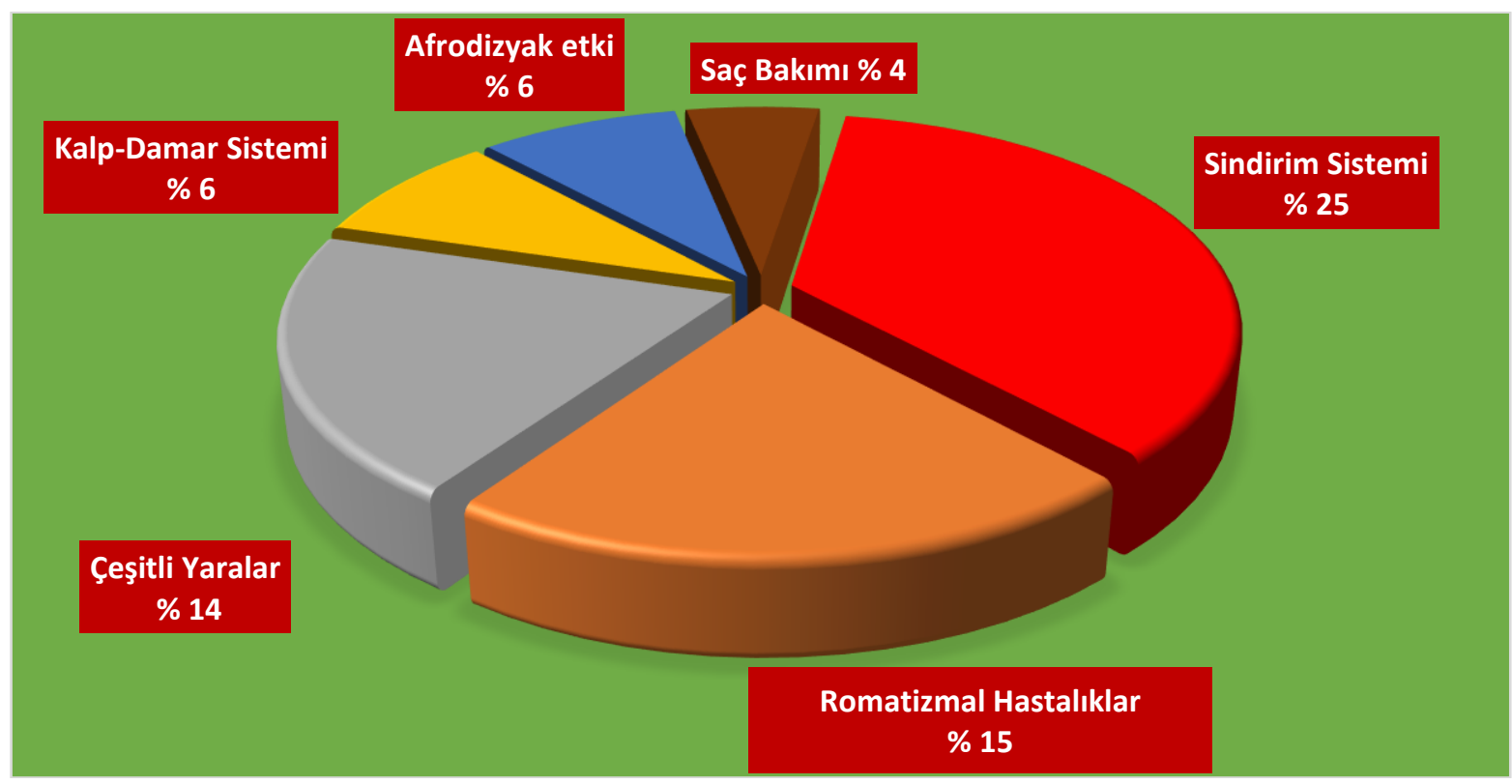

Şekil 3. Çalışmada tespit edilen bitkilerin kullanım alanları 

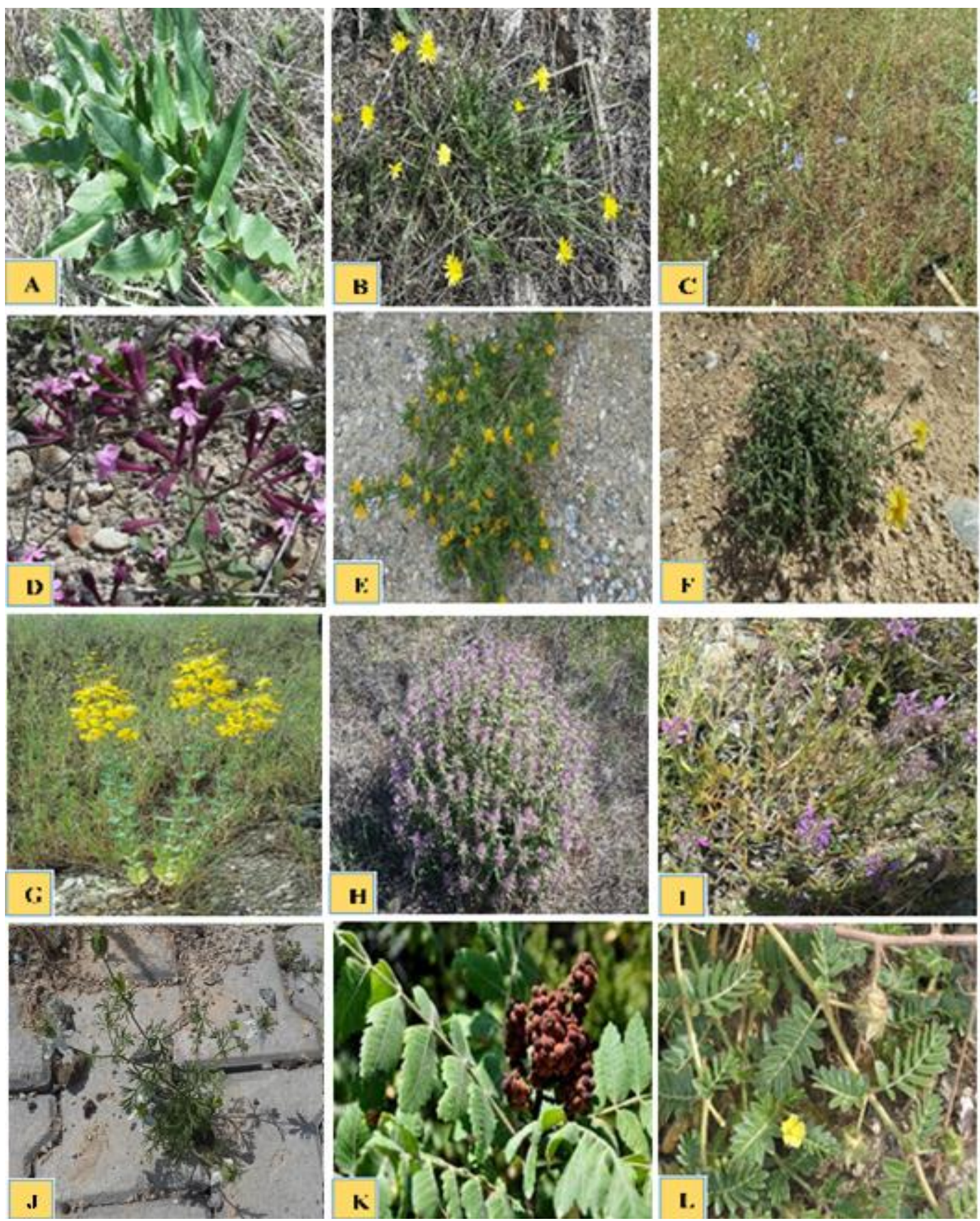

Sekil 4. Araștırma alanında tespit edilen bazı bitkilere ait fotoğraflar; A) Arum dioscoridis var. sriacum, B) Chondrilla juncea, C) Cichorium intybus, D) Saponaria officinalis, E) Scolymus hispanicus, F) Helianthemum salicifolium, G) Hypericum lydium, H) Phlomis pungens var. hirta, I) Thymus kotschyanus, J) Nigella arvensis var. glauca, K) Rhus coriaria, L) Tribulus terrestris

Zeytin (Olea europaea subsp. europaea) bölgede önemli bir gıda olmakla beraber romatizmal ağrılar için zeytinyağı tercih edilirken, yaprakları şeker hastalığı tedavisinde kullanılmaktadır. Son yıllarda kullanımı ve yetiştirilmesi çok yaygınlaşan nar (Punica granatum) meyvesinden elde edilen nar ekşisi ekonomik bir ürün haline dönüşmüş, bölgede ağız yarası tedavisinde ve kalp rahatsızlıkları için kullanılmaktadır. Glycyrrhiza glabra var. glabra (Mayam)'dan hazırlanan şerbet yaz aylarında serinletici ve sindirim sistemini rahatlatıcı olarak yoğun bir şeklide tüketilmektedir. Juglans regia (ceviz) yaprakları saç bakımı için kullanılırken meyvesi 
gıda olarak tüketilmektedir. Tespit edilen 9 takson sindirim sistemi rahatsızlıkları için (Arum dioscoridis var. syriacum, Cichorium intybus, Convolvulus arvensis, Convolvulus scammonia, Mentha longifolia, Glycyrrhiza glabra var. glabra, Scolymus hispanicus, Ficus carica subsp. carica, Morus alba), 7 takson çeşitli ağnılar için (Eriobotrya japonica, Hypericum lydium, Olea europaea subsp. europaea, Paliurus spina-christi, Solanum americanum, Urtica dioica subsp. dioica, Veronica cymbalaria), kullanılmaktadır (Tablo 2). Bölgede doğal olarak yetişen Rhus coriaria (Sumak) tohumlarınden dekoksiyon yöntemiyle elde edilen "Sumak ekşisi” ağız yarası tedavisinde ve yemeklere lezzet vermek amacıyla kullanılmaktadır. Bu tür mide krampları için farklı bölgelerde kullanılmaktadır [8, 23]. Tribulus terrestris L. (çoban çökerten) afrodizyak etkisi nedeniyle ve damar açıcı özelliği için kullanılmaktadır. Xanthium spinosum (pıtrak) tohumları şeker hastalığı tedavisinde kullanılmaktadır. Urtica diocia bölgede genellikle saç bakımı ve romatizmal ağrılar için kullanılırken farklı çalışmalarda bu kullanımın yanısıra idrar artırıcı ve sindirim kolaylaştırıcı özelliğinden de bahsedilmektedir [23]. Elaeagnus angustifolia meyveleri şeker hastalığı ve üriner sistem rahatsızlıkları için kullanılırken [24] bölgede nefes darlığı tedavisinde kullanılmaktadır. Paliurus spina-christi’nin olgunlaşmış meyveleri kaynatılarak elde edilen sıvı içilerek ve masaj yapılarak kas krampları ve eklem ağrıları için kullanılmaktadır. Juglans regia yapraklarının şeker hastalığına iyi geldiği düşünülmektedir.

Tablo 2. Araştırma alanında tespit edilen bitkilerin tıbbi yönleri

\begin{tabular}{|c|c|c|c|c|}
\hline Familya Adı & Bilimsel Adı & Yöresel Adı & Kullanılan Kısım & Kullanım Amacı \\
\hline Anacardiaceae & Rhus coriaria $\mathrm{L}$. & Sumak & Tohum & Ağ1z yaraları için \\
\hline Araceae & $\begin{array}{l}\text { Arum dioscoridis SM. var. } \\
\text { syriacum }\end{array}$ & Tirşik & Yaprak & $\begin{array}{l}\text { Sindirim Sistemi } \\
\text { rahatsızlıkları }\end{array}$ \\
\hline Araliaceae & Hedera helix L. & Sarmaşık & Yaprak & Öksürük kesici \\
\hline Asteraceae & Chondrilla juncea $\mathrm{L}$. & Çitlık & Yaprak & Yara iyileştirici \\
\hline Asteraceae & Cichorium intybus L. & Çitlık & Yaprak ve çiçek & Mide rahatlatıcı \\
\hline Asteraceae & $\begin{array}{l}\text { Crepis foetida L. subsp. } \\
\text { rhoeadifolia M.(Bieb.) Celak. }\end{array}$ & Hindiba & Toprak üstü kısım & Damar açıcı \\
\hline Asteraceae & $\begin{array}{l}\text { Scolymus hispanicus L. subsp. } \\
\text { Hispanicus }\end{array}$ & Sarı diken & Toprak üstü kısım & $\begin{array}{l}\text { Sindirim sistemi } \\
\text { rahatsızlıkları }\end{array}$ \\
\hline Asteraceae & Xanthium spinosum L. & Pitrak & Tohum & Şeker hastalığı \\
\hline Brassicaceae & $\begin{array}{l}\text { Capsella bursa-pastoris (L.) } \\
\text { Medik. }\end{array}$ & Çıngırak otu & Toprak üstü kısım & Yara iyileştirici \\
\hline Brassicaceae & Nasturtium officinale R.Br. & Ispatan & Yaprak & Bağışıklık sistemi \\
\hline Brassicaceae & Raphanus raphanistrum L. & Turp & Meyve & İştah açıcı \\
\hline Caryophyllaceae & Saponaria officinalis L. & Sabun otu & Toprak üstü kısım & Mikrop öldürücü \\
\hline Caryophyllaceae & $\begin{array}{l}\text { Vaccaria hispanica (Mill.) } \\
\text { Rauschert }\end{array}$ & Bakla otu & Kök & İdrar artırıcı \\
\hline Convolvulaceae & Convolvulus arvensis L. & Sarmaşık & Toprak üstü kısım & Bağırsak parazitleri \\
\hline Convolvulaceae & Convolvulus scammonia L. & Sarmaşık & Yaprak & Mide krampları \\
\hline Elaeagnaceae & Elaeagnus angustifolia L. & İğde & Meyve, tohum & Nefes açıcı \\
\hline Fabaceae & Glycyrrhiza glabra L. var. glabra & Mayam & Kök & $\begin{array}{l}\text { Serinletici ve mide } \\
\text { rahatlatıcı }\end{array}$ \\
\hline Hypericaceae & Hypericum lydium Boiss. & Kantaron & Toprak üstü kısım & $\begin{array}{l}\text { Romatizma ağrıları ve } \\
\text { sakinleştirici }\end{array}$ \\
\hline
\end{tabular}




\begin{tabular}{|c|c|c|c|c|}
\hline Familya Adı & Bilimsel Adı & Yöresel Adı & Kullanılan Kısım & Kullanım Amacı \\
\hline Juglandaceae & Juglans regia $\mathrm{L}$. & Ceviz & Yaprak, meyve & $\begin{array}{l}\text { Saç bakımı, şeker } \\
\text { hastalığı }\end{array}$ \\
\hline Lamiaceae & Mentha longifolia $\mathrm{L}$. & Nane & Yaprak & Sindirim kolaylaştırıcı \\
\hline Lamiaceae & Ocimum basilicum $\mathrm{L}$. & Reyhan & Yaprak & Mikrop öldürücü \\
\hline Lamiaceae & $\begin{array}{l}\text { Phlomis pungens Willd. var. hirta } \\
\text { Velen. }\end{array}$ & Tüylü dağ çayı & Yaprak & Yara iyileştirici \\
\hline Lamiaceae & Rosmarinus officinalis L. & Biberiye & Yaprak ve çiçek & Soğuk algınlığ 1 \\
\hline Lamiaceae & Salvia palaestina Benth. & Dağ çayı & Yaprak & Soğuk algınlığı \\
\hline Lamiaceae & $\begin{array}{l}\text { Thymus kotschyanus Boiss. \& } \\
\text { Hohen }\end{array}$ & Kekik & Toprak üstü kısım & Soğuk algınlığ 1 \\
\hline Lamiaceae & Ziziphora capitata L. & Zahter & Yaprak, çiçek & Tansiyon düşürücü \\
\hline Lauraceae & Laurus nobilis L. & Defne & Yaprak & Saç bakımı \\
\hline Malvaceae & $\begin{array}{l}\text { Abelmoschus esculentus (L.) } \\
\text { Moench }\end{array}$ & Bamya & Meyve & Sinüzit tedavisi \\
\hline Malvaceae & Malva nicaeensis All. & Kömeç & Yaprak & Kadın hastalıkları \\
\hline Moraceae & Morus nigra L. & Urmu dutu & Meyve & İștah açıcı, ağız yarası \\
\hline Moraceae & Morus alba $\mathrm{L}$. & Beyaz dut & Meyve & $\begin{array}{l}\text { Kan yapıc1, Sindirim } \\
\text { rahatlatıc1 }\end{array}$ \\
\hline Oleaecae & $\begin{array}{l}\text { Olea europaea L. subsp. } \\
\text { europaea }\end{array}$ & Zeytin & Meyve, yaprak & $\begin{array}{l}\text { Romatizmal ağrılar, } \\
\text { şeker hastalığ } 1\end{array}$ \\
\hline Pinaceae & Pinus pinea $\mathrm{L}$. & Çam fistığ 1 & Tohum & Afrodizyak \\
\hline Plantaginaceae & Veronica cymbalaria Bodard & Venüs otu & Toprak üstü kısım & Kas ağriları \\
\hline Portulacaceae & Portulaca oleracea $\mathrm{L}$. & Soğukluk & Yaprak & $\begin{array}{l}\text { Bağışsılık sistemi, } \\
\text { zekâ gelişimi }\end{array}$ \\
\hline Punicaceae & Punica granatum $\mathrm{L}$. & Nar & Meyve & $\begin{array}{l}\text { Ağız yarası, kalp } \\
\text { hastalıkları }\end{array}$ \\
\hline Ranunculaceae & $\begin{array}{l}\text { Nigella arvensis L. var. glauca } \\
\text { Boiss. }\end{array}$ & Çörek otu & Tohum & İştah açıcı \\
\hline Rhamnaceae & Paliurus spina-christi P. Mill. & Karaçalı & Tohum & $\begin{array}{l}\text { Kas krampları, eklem } \\
\text { ağrıları }\end{array}$ \\
\hline Rosaceae & $\begin{array}{l}\text { Crataegus monogyna Jacq. var. } \\
\text { monogyna }\end{array}$ & Alıç & Gövde & Kalp ve damar sistemi \\
\hline Rosaceae & $\begin{array}{l}\text { Eriobotrya japonica (Thunb.) } \\
\text { Lindl. }\end{array}$ & Yenidünya & Yaprak & $\begin{array}{l}\text { Romatizma tedavisi, } \\
\text { nefes açıcı }\end{array}$ \\
\hline Rosaceae & Rosa canina $\mathrm{L}$. & Kuşburnu & Kök & Nefes darlığı \\
\hline Solanaceae & Solanum melongena $\mathrm{L}$. & Patlican & Meyve sap1 & Hemoroid tedavisi \\
\hline Solanaceae & Solanum americanum Mill. & İt üzümü & Kök & Romatizmal ağrilar \\
\hline Urticaceae & Urtica dioica L.subsp. dioica & Isırgan otu & Yaprak & $\begin{array}{l}\text { Romatizmal ağrilarda, } \\
\text { saç bakımı, }\end{array}$ \\
\hline Vitaceae & Vitis vinifera $\mathrm{L}$. & Asma & Yaprak & Yara iyileştirici \\
\hline Zygophyllaceae & Tribulus terrestris L. & Çoban çökerten & Toprak üstü kısım & $\begin{array}{l}\text { Damar açıcı, } \\
\text { afrodizyak, böbrek taşı }\end{array}$ \\
\hline
\end{tabular}

\section{SONUÇLAR}

$\mathrm{Bu}$ araştırma ile Kahramanmaraş Sütçü İmam Üniversitesi Avşar Kampüsü ve çevresindeki alanda bulunan farklı familyalara ait 47 bitki taksonunun tıbbi amaçlar için kullanımları araştırılmıştır. Bu tür bitkiler bölgede doğal olarak yetişmekte ve bölge insanı bu türlere kolayca ulaşabilmektedir. Ayrıca besleyici özellikte olmaları, içerdikleri sekonder metabolitlerden dolayı tıbbi özellik taşımaları ve farklı amaçlar için kullanılabilir olmaları bu türlerin tercih sebebidir. Tıbbi özellikte olan türlerin kullanım şekillerin ve miktarları konusunda dikkatli 
olunması gerekir. Farklı kullanım şekilleri tespit edilen bitkilerin büyük kısmı doğadan toplanarak değerlendirilmektedir. Dünya nüfusunda öngörülen artış ve tahmin edilen nüfus doğal kaynakların daha da azalmasına neden olacaktır. Bitkilerin bilinçsiz ve ihtiyaç dışı toplanması gelecekte birçok taksonun neslini tehlikeye sokması mümkündür. Etnobotanik araştırmalar ile elde edilen geleneksel bilgiler yılların birikimi ile elde edilen ve tecrübeye dayanan paha biçilemez kültürel bir değerdir. Mevcut araştırmalar ile tespit edilen bu bilgilerin bilimsel bilgi ile bütünleştirilerek değerlendirilmesi önemlidir. $\mathrm{Bu}$ araştırmanın diğer etnobotanik çalışmalarla birleştirilerek Türkiye'nin bu açıdan zengin yapısının ortaya çıkarılmasına ve farklı alanlarda yapılabilecek çalışmalara fikir vermesi olasıdır.

\section{KAYNAKLAR}

[1] T. Tütenocaklı, Ayvacık (Çanakkale) ve Çevresinin Etnobotanik Bir Çalışma. XVII. Ulusal Biyoloji Kongresi, 21-24 Haziran, Adana, Turkey, (2004).

[2] S. Y1ldırıml1, Etnobotanik ve Türk Etnobotaniği. Kebikeç İnsan Bilimleri için Kaynak Araştırmaları Dergisi, 17 (2004) 175-193.

[3] Y.Z. Kocabaş, O. Gedik, Kahramanmaraş Il Merkezi Semt Pazarlarında Satılan Bitkiler Hakkında Etnobotanik Araştırmalar. Iğdır Univ. J. Inst. Sci. \& Tech. 6(4) (2016) 41-50.

[4] D.J. Chadwick, J. Marsh, Ethnobotany and the search for new drugs. In: Ciba Foundation Symposium, Wiley, Chichester, 185 (1994) 42-60.

[5] T. Baytop, Therapy with Medicinal Plants in Turkey (Past and present). İstanbul: İstanbul University Publications, (1984) 520.

[6] M. Kargıŏglu, S. A. Cenkçi, N. Evliyaoğlu, M. Konuk, M.Ş. Kök, Y. Bağcı, An ethnobotanical survey of inner-west Anatolia Turkey. Human Ecology, 36 (2008) 763777.

[7] S. Demirci, N. Özhatay, An Ethnobotanical Study in Kahramanmaraş (Turkey); Wild Plants Used For Medicinal Purpose in Andırın, Kahramanmaraş. Turkish Journal of Pharmaceutical Sciences, 9(1) (2012) 75-92.

[8] H. Akan, Y. Bakır, Kâhta (Adıyaman) Merkezi ve Narince Köyü’nün Etnobotanik Açıdan Araştırılması, BEÜ Fen Bilimleri Dergisi, 4(2) (2015) 219-248.

[9] T. Günbatan, İ. Gürbüz, A. Gençler, The current status of ethnopharmacobotanical knowledge in Çamlıdere (Ankara, Turkey). Turkish Journal of Botany, 40 (2016) 241249.

[10] WHO, World Health Organization, Traditional Medicine Strategy 2002-2005. Geneva, Switzerland, (2002).

[11] T. Garnatje, J. Penuelas, J. Valles, Ethnobotany, Phylogeny, and 'Omics' for Human Health and Food Security. Trends in Plants Science, 22:3 (2017) 187-191.

[12]N. Sadıkoğlu, Cumhuriyet Dönemi Türk Etnobotanik Araştırmalar Arşivi. İstanbul Üniversitesi, Sağlık Bilimleri Enstitüsü, (Basılmamış) Yüksek Lisans Tezi, (1998) 106.

[13]S. Başaran, Elmalı Yöresinde Doğal Olarak Yetişen Bazı Bitkilerin Etnobotanik Özellikleri, Batı Akdeniz Ormancılık Araştırma Müdürlüğü Dergisi, 211:5 (2003) 8-18. 
[14] J.B. Hudson, M.K. Lee, B. Şener, N. Erdemoğlu, Antiviral activities in extracts of Turkish medicinal plants. Pharmaceutical Biology, 38 (3) (2000) 171-175.

[15] T. Baytop, Türkiye'de Bitkiler ile Tedavi. İstanbul: Nobel Tıp Kitabevleri, (1999).

[16] P.H. Davis, Flora of Turkey and The East Aegean Islands. Vol. 1-9, Edinburgh:Edinburgh University Press, (1965-1985) .

[17] A. Güner, S. Aslan, T. Ekim, M. Vural, M.T. Babaç, (edlr). Türkiye Bitkileri Listesi (Damarlı Bitkiler), Nezahat Gökyiğit Botanik Bahçesi ve Flora Araştırmaları Derneği Yayınları, İstanbul, (2012) 1290.

[18] Anonim, Kahramanmaraş Büyükşsehir Belediyesi. http://kahramanmaras.bel.tr. (Erişim tarihi 20 Nisan, 2016)

[19] Anonim, Kahramanmaraş İli Toprak Kaynağı Envanter Raporu, Ankara, (1973).

[20] Y. Akman, İklim ve Biyoiklim Biyoiklim Metodları ve Türkiye İklimleri. Ankara: Palme yayınları, (1990).

[21]R. Gündoğan, A. Demirkıran, K. Yılmaz, KSÜ Yerleşkesi Detaylı Toprak Etüd Haritalama Proje Raporu (1996).

[22]Ç. Kızılarslan, İzmit Körfezi’nin Güney Kesiminde Etnobotanik Bir Araştırma. İstanbul Üniversitesi Sağlık Bilimleri Enstitüsü, (Basılmamış) Yüksek Lisans Tezi, (2008).

[23] R. Polat, S. Selvi, U. Çakılcıŏlu, M. Acar, Investigations of ethnobotanical aspect of wild plants sold in Bingöl (Turkey) local markets. Biological Diversity and Conservation, 5(3) (2012) 155-161.

[24]E. Sezik, M. Tabata, E. Yeşilada, G. Honda, K. Goto, Y. Ikeshiro, Traditional medicine in Turkey. I. Folk medicine in Northeast Anatolia. Journal of Ethnopharmacology, 35 (1991) 191-196. 